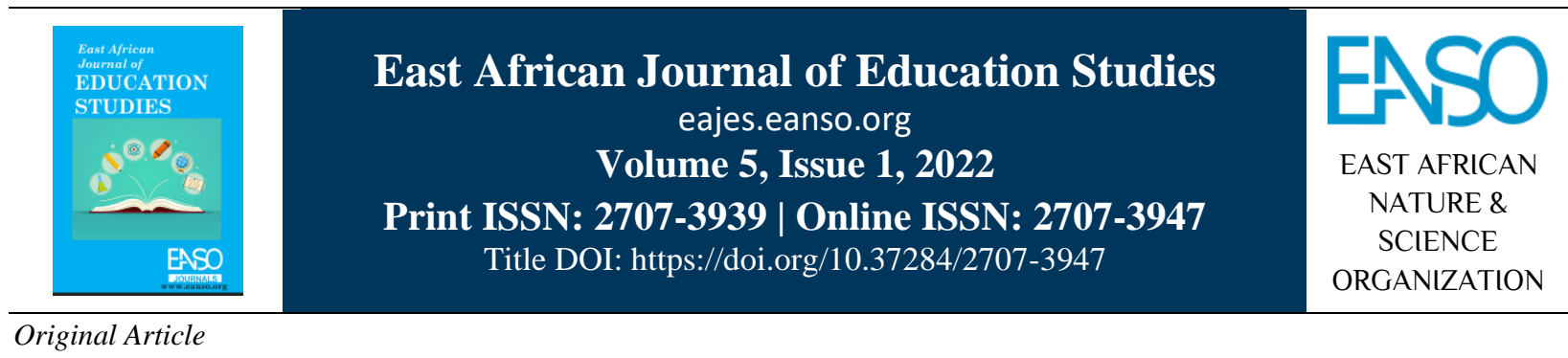

\title{
Effectiveness of Pre-School Teachers in Implementing English and Math Curricular in Nyamagana District, Tanzania.
}

\author{
Daniel Oduor Onyango ${ }^{*} \&$ Sr. Demetria Mkulu ${ }^{1}$ \\ ${ }^{1}$ St. Augustine University of Tanzania, P. O. Box 307, Mwanza, Tanzania. \\ * Author for Correspondence ORCID ID: https://orcid.org/0000-0002-5381-226X; Email: jumadan06@ gmail.com.
}

Article DOI: https://doi.org/10.37284/eajes.5.1.575

\section{Date Published: ABSTRACT}

08 March 2022 Teachers are key to effective implementation of the preschool curriculum,

Preschool Curriculum, Math Curriculum, English Curriculum, Curriculum Implementation. especially in areas related to the acquisition of basic literacy skills which are necessary foundations for other levels of education. The purpose of the study was to assess the effectiveness of preschool teachers in handling preschool English and Math curricula in the Nyamagana District. The study was guided by the following specific objectives to find out if preschool teachers have relevant skills in handling of preschool English curriculum and to establish whether preschool teachers had relevant skills in the teaching of the Math curriculum. The population for the study was 100 preschools. This included 100 head teachers and 410 preschool teachers. The sample for this study was 100, inclusive of included 20 head teachers and 82 teachers. Simple random sampling was used to select teachers and headteachers who took part in the study. Descriptive statistics was used to analyze quantitative data with the help of Statistical Package for Social Sciences (SPSS) version 20. Moreover, qualitative data was analyzed thematically. The responses from the open-ended part of the questionnaire were subjected to thematic analysis. The study found that majority of teachers had relevant skills in handling the preschool Math curriculum. However, some teachers could not handle certain aspects of the Math curriculum. Also, the study found out that the majority of preschool teachers could effectively implement the English language curriculum; however, a few teachers had challenges, such as using the medium of songs. The study recommended that there is a need to conduct workshops and refresher seminars for teachers in order to equip them with skills to effectively implement English and Math curricula in preschools.

117 | This work is licensed under a Creative Commons Attribution 4.0 International License. 


\section{APA CITATION}

Onyango, D. O., \& Mkulu, D. (2022). Effectiveness of Pre-School Teachers in Implementing English and Math Curricular in Nyamagana District, Tanzania. East African Journal of Education Studies, 5(1), 117-125. https://doi.org/10.37284/eajes.5.1.575.

\section{CHICAGO CITATION}

Onyango, Daniel Oduor., \& Demetria Mkulu. 2022. "Effectiveness of Pre-School Teachers in Implementing English and Math Curricular in Nyamagana District, Tanzania”. East African Journal of Education Studies 5 (1), 117-125. https://doi.org/10.37284/eajes.5.1.575.

\section{HARVARD CITATION}

Onyango, D. O. \& Mkulu, D. (2022) "Effectiveness of Pre-School Teachers in Implementing English and Math Curricular in Nyamagana District, Tanzania”, East African Journal of Education Studies, 5(1), pp. 117-125. doi: 10.37284/eajes.5.1.575.

\section{IEEE CITATION}

D. O. Onyango, \& D. Mkulu, "Effectiveness of Pre-School Teachers in Implementing English and Math Curricular in Nyamagana District, Tanzania”, EAJES, vol. 5, no. 1, pp. 117-125, Mar. 2022.

\section{MLA CITATION}

Onyango, Daniel Oduor., and Demetria Mkulu. "Effectiveness of Pre-School Teachers in Implementing English and Math Curricular in Nyamagana District, Tanzania". East African Journal of Education Studies, Vol. 5, no. 1, Mar. 2022, pp. 117-125, doi:10.37284/eajes.5.1.575.

\section{INTRODUCTION}

The future of a country is in the hands of its children; what the society expects to be in future, it must prepare its young ones for that future. Teachers are key to effective implementation of the preschool curriculum, especially in areas related to the acquisition of basic literacy skills which are necessary foundations for other levels of education. Poor handling of curriculum at preschool level can be catastrophic for higher levels of education, especially in Science, Maths, and Languages (National Association for the Children, 2016). In addition to this, a teacher who does not have adequate knowledge about child developmental milestones will not be able to integrate this information in planning relevant learning activities. This is likely to contribute to massive disservice to learners (Young, 1997).

Tanzania Institute of Education (TIE) has developed a curriculum for preschools in Tanzania which has been adopted in all schools. Through this curriculum, the government of Tanzania envisages the preparation of learners who can contribute to the socio-economic development of Tanzania, an industrialized country. It is also expected that the curriculum would equip learners with skills to be able to live in a dynamic changing world and changes in science and technology (TIE, 2016). This means that government relies in teaching to effectively implement a preschool curriculum in order for the national goals of education to be realized (Onyango, 2020). In this study, curriculum and syllabus will be used alternatively.

The developers of the curriculum envision that those teachers who would implement the preschool curriculum would be those who are prepared to teach at that level of education. However, studies show that many preschool teachers were not implementing preschool curricula as expected due to inadequate knowledge about the curriculum they required to implement. Also, studies reviewed indicate that much has not been done to assess the effectiveness of teachers in handling Math, Science, and English curriculum in preschool (Onyango, 2008). Therefore, this current study sought to build up knowledge on the effectiveness of teachers in handling Maths and English curricula.

\section{Statement of the problem}

The requirement for effective curriculum implementation includes teachers having knowledge about the subjects, relevant knowledge, and skills on how to use various teaching methods, especially play; teachers are able to use various learning resources and creativity; be able to build a very strong working relationship with children. According to reports by Uwezo (2014), many pupils who enrolled in class one and have gone through preschool lack rudimentary skills in Science, Math, and English: writing and reading. Poor performance 
in Maths and Sciences at preschool can contribute to deficiency in the acquisition of science skills at higher levels of education. If these challenges are not addressed, Tanzania as a country may face inadequate scientists and other technical people because the system of education did not equip learners with Math, Science and English skills at the preschool level and this may affect the country's ability to achieve its economic blueprint of becoming industrialized. This motivated the researchers to carry out this study.

\section{General Objective}

The purpose of the study is to assess the effectiveness of preschool teachers in handling preschool English and Math curricula in the Nyamagana District. The study was guided by the following specific objectives:

- To find out if preschool teachers have relevant skills in handling of preschool English curriculum

- To establish whether preschool teachers had relevant skills in the teaching of Math curriculum

\section{Significance of the Study}

The study is significant as it identified challenges that teachers face in the teaching of Maths and English. The findings will be useful to curriculum developers for they will the knowledge generated to improve implementation of the preschool curriculum. Adoption of the findings will also contribute to the adoption of better training methodologies for preschool teachers in Tanzania. The study might also contribute to increased funds for the acquisition of materials to enhance early learning of Math, Science and English at a preschool level.

\section{THEORETICAL FRAMEWORK}

The study was guided by the implementation of educational innovations theory (Gross et al., 1971). In this theory, Gross and colleagues explain that in the implementation of educational innovation, certain factors need to be considered in order for the implementation to be successful. Gross et al. (1971) list the factors in the following order
- Awareness to clarity

- Availability of facilities

- Administrative support

- Knowledge and skills

- Attitude of the implementation

The author argues that if the factors are not properly taken care of, then implementation becomes very difficult and innovation cannot achieve its intended goal of benefiting the recipients. This study considers the preschool level of education in Tanzania as an innovation whose purpose is to give children a strong foundation in English and Maths. These are the subjects that are required in preparing future scientists, economists, and statisticians. Teachers cannot prepare this calibre of learners if they do not have the necessary skills and competencies to effectively implement the preschool curriculum.

Therefore, the implementation of educational innovations theory is relevant to this study as it assisted the researchers to assess whether teachers had the required knowledge to enable them to implement the English and Math preschool curriculum effectively as desired by the Tanzania Institute of Education. The researchers were satisfied that since the model had been employed by other scholars, then it would guide them to complete the project.

\section{LITERATURE REVIEW}

\section{Preschool Teachers and Implementation of Preschool English Curriculum}

Children can acquire a language on their own. Stark (1980) suggests that children acquire language through the following stages: crying, cooing and laughter, vocal play, and babbling. He further indicates that adults should support children in their learning by serving as models, through exposing a child to language through talks and reinforcing child learning of the language by clapping, tolerance, smiling back, and listening attentively. Chomsky (1995) who is a well-known language theorist, argues that language acquisition device is present in the brains of children. It enables the children to 
process the language. This inborn ability can only be realized in a situation where the child is encouraged and interacted with. Therefore, there is a need for a child to experience some stimulation from the environment. Teachers need to kick start learners' acquisition of learning a new language by providing children with an interactive environment and meaningful activities which will support the learning.

Preschool education helps children to develop and master language skills which are important as a medium for communication. Furthermore, a good preschool education improves the ability of children to excel in primary education and this is not possible without the contributions of qualified teachers. Teachers are key to the implementation of a curriculum. They need to possess requisite skills in order for them to implement a curriculum effectively. Richardson (2008) conducted a study in Alabama, USA and came up with the findings that there is a significant relationship between teachers' qualifications and students' achievements. These findings agree with the study done in Migori County in Kenya by Ojera (2016), which revealed that pupils taught by teachers with higher qualifications had better performance than those taught by teachers with low qualifications. The later assertions are important in this study as they will help the researcher to interpret the findings with respect to how the qualification of teachers has affected the implementation of the English preschool curriculum in the Nyamagana District.

On the other hand, Bruns et al. (2011) outlined that teacher performance can be affected by incentives, both monetary and no-monetary, and factors that motivate teachers' performance: ranging from basic salaries and pensions, intrinsic motivation, mastery, adequate infrastructure and teaching materials, and recognition and prestige. These factors can affect the effectiveness of qualified, motivated, effective teachers.

Further, Torto (2017) asserts that pupils have not been born into the language, so they are bound to have many setbacks in learning the language, especially where the teacher is also a second speaker of the language. And it therefore demands that a teacher who has received adequate training in this subject should handle pupils in order not to put pupils' future in jeopardy. Such a teacher is in a better condition to use current approaches and methods. Thus, researchers in the current study aimed to find out if preschool teachers have relevant skills in handling of preschool English curriculum.

Nyokabi (2018) recommended that there should be programs on in-service training among preschool teachers to enable them to handle the diversities in characters among learners and also to implement the curriculum properly. Training enhances the professional development of preschool teachers, which results in the effective implementation of the English curriculum.

\section{Preschool Teachers Skills and Teaching of Math Curriculum}

Maths is very important in the life of children. In their later life's they will require Maths skills to be able to survive in this life. Ministry of Education (MoEST, 2016) asserts that Maths is a concept or an idea that develops in the minds of the children through the experience. To help children develop Maths concepts, teachers need to expose learners to concrete experiences in order to help the learners to understand Maths better.

According to Gichuru (2016), teachers' qualifications had a positive influence on pupils' mathematics performance. Furthermore, teachers' choice of teaching strategies is critical to learning. Children, unlike adults who easily learn through non-participatory methods, require concrete experiences. According to Gerdes, Durden and Poppe (2013), preschoolers are well known for their focus on self, concrete ideas, exploratory interactions, and less complex thinking. These experiences enable children to make sense of the world, to be able to communicate their ideas and to show initiative.

Juma (2014) conducted a study on the factors which contributed to teachers' use of music as a medium of instruction. The study revealed factors such as teacher training, teacher qualifications, and attitude towards the use of music as a medium of instruction. This study is useful as it shows the link between attitude, qualification and how they influence the choice of a teaching method. Poor selection of teaching methods can seriously affect learning at a preschool level. 
In addition to that, Japhet (2016) who conducted a study in Tanzania on teachers scaffolding young children's mathematics learning activities in preprimary schools, found that teachers were not aware of mathematics learning activities as stipulated in the syllabus. And most of them lack a pre-primary syllabus and guidelines. This information will assist researchers to establish the link between teacher qualification and teaching of Mathematics in the Nyamagana District.

Thus, researchers in this current study sought to assess the effectiveness of preschool teachers in handling preschool English and Math curricula in the Nyamagana District.

\section{RESEARCH METHODOLOGY}

This section describes the research approach, design, and instruments that were used in the study.

\section{Research Approach}

This study deployed a mixed research approach. This strategy allowed the researcher to collect both qualitative and quantitative data in the same study. The strategy assisted the researchers to collect a variety of data which would not have been possible if mono method had been deployed. This approach strengthened the study as both qualitative and quantitative were integrated into a single study (Oso \& Onen, 2008).

\section{Research Design}

The design of the study was a descriptive survey which allowed large amounts of data to be collected over a short period of time. Through it, the researchers were able to describe the effectiveness of preschool teachers in implementing preschool English and math curricular relationships between independent and dependent variables (Calmorin \& Calmorin, 2007).

\section{Instrumentation}

In the study, the researcher employed a semistructured questionnaire in the collection of data.

\section{Questionnaires}

The questionnaire had both closed and open-ended questions. The researcher applied this method to collect data from preschool teachers and headteachers because it could take a short time. The researchers distributed the questionnaire to teachers and gave them time to complete the questionnaire before collecting the completed questionnaire.

\section{Population of the Study}

The population is defined as a group of individuals, objects, or items from which samples are taken for measurement. Hence, the population for the study was 510, which included 100 head teachers and 410 teachers (Kombo and Tromp, 2006); Anderson, 1987).

\section{Sample Size and Sampling Techniques}

The respondents of this study were 100 people; this included 20 head teachers and 80 teachers. According to Gay, Mills and Airasian (2012), 10-30 per cent of a defined population is adequate to represent as a sample. Simple random sampling was used in selecting respondents in this study. Simple random sampling is the process of selecting a sample in such a way that all individuals in the defined population have an equal chance of being included in the study (Gay, Mills and Airasian, 2012). The method used to carry out random sampling was the lottery method.

\section{Data Analysis}

Creswell (2012) defines data analysis as the act of developing a common sense of the data and then coding descriptions and themes about the central phenomena. The study applied a mixed approach, quantitative and qualitative techniques of data analysis. In quantitative data, descriptive statistics was used to analyze quantitative data with the help of Statistical Package for Social Sciences (SPSS) version 20. Data was presented in the form of a single table where\%ages were used. Moreover, qualitative data from the open-ended section of the questionnaire was analyzed thematically. 


\section{Ethical Considerations}

Research involving the study of preschool teachers is a very sensitive activity that involves revealing weaknesses in the preschools in Tanzania. To address these concerns, the researchers communicated the following to headteachers and teachers who were respondents; what was being studied, the purpose of the study, who are involved in the study, the methods to be used in the collection of data, and the usefulness of the findings to the preschools' education in Tanzania. The ethical issues were highly emphasized in order to protect the rights of the respondents and the researcher (Best \& Khan, 2006).

The respondents were informed comprehensively about the nature and purpose of the research, the procedures to be used, and the expected benefits to the preschools in Tanzania. The respondents' participation in the study was voluntary. The researcher assured the respondents of their confidentiality. The researcher informed the respondents of their right to withdraw from participation in case they had any challenges with the study (Krysik \& Finn, 2007).

\section{RESULTS AND DISCUSSIONS}

The first objective of the study sought information from respondents on whether preschool teachers had skills in handling preschool English language syllabus. Results are shown in Table 1. The instrument was prepared in English and then translated into Kiswahili. The majority of teachers who teach in preschools are comfortable using Kiswahili as opposed to English.

The respondents were given statements and they were expected to indicate their level of agreement with the statement.

Table 1: Teacher's ability to implement preschool curricula (\%)

\begin{tabular}{|c|c|c|c|c|c|}
\hline & SA & $\mathbf{A}$ & NO & $\mathbf{D}$ & SD \\
\hline \multicolumn{6}{|l|}{ English Language } \\
\hline Able to use songs, stories, riddles to help a learner develop speech & 26.7 & 51 & 44 & 2.2 & 15.6 \\
\hline Able to prepare materials to be used to teach reading skills & 37.8 & 31.1 & 17.8 & 6.7 & 6.7 \\
\hline Able to teach doodling & 35.6 & 35.6 & 13.3 & 4.4 & 11.1 \\
\hline Able to teach songs related to alphabetic sounds & 46.7 & 26.7 & 8.9 & 11.1 & 6.7 \\
\hline \multicolumn{6}{|l|}{ Math } \\
\hline Comfortable in teaching numbers concepts, symbols & 37.8 & 37.8 & 8.9 & 6.7 & 8.9 \\
\hline Able to use creative arts such as songs to teach numbers & 42.2 & 44.4 & 4.4 & 6.7 & 8.9 \\
\hline
\end{tabular}

Key: SA: Strongly Agreed; A: Agree; NO, Neutral; D: Disagree; SD: Strongly Disagree

The respondents were required to show their ability to implement language curriculum by using the medium of songs, ability to develop materials, and ability to teach doodling and basic sounds. Table 1 shows that 26\% strongly agreed and 51\% agreed that they can use songs and riddles; another 37\% strongly agreed, $31 \%$ agreed that they are able to prepare materials. This result suggests that majority of preschool teachers are able to handle the English syllabus. It is only a minority who indicated that they had a problem in handling the various aspects of English syllabus. This implies that there are some teachers who are teaching in preschools but they have not acquired core skills to facilitate teaching and learning of English language to preschool children.
The skill which the majority of teachers (17.8\%) are not able to handle is use of songs. This was followed by ability to use songs related to alphabet. The finding depicts a situation in preschools in Nyamagana District where some teachers lack some critical skills. Suppose these teachers who cannot use songs and riddles to teach English are found in one particular school it will disadvantage the children greatly.

Preschool curriculum in Tanzania prepares 3-5year-olds for primary education therefore poor acquisition of basic English language skills such as reading at this level will affect these children in later stages of their education. There is need to hire teachers who are familiar with developing language 
teaching materials, teaching speech, and theories of language development.

These findings agree with assertions by Uwezo (2014) that poor reading writing skills prevalent in Tanzanian primary schools could be traced to poor implementation of English syllabus at preschool level of education. The current study shows that a number of preschool teachers do not have required skills to implement English curriculum effectively. The same findings about a number of teachers not able to handle some aspect of the English syllabus confirms assertions by Gross et al. (1971) in the implementation of curriculum theory who claimed that many innovations fail to achieve their goal because a group of implementers often lack required skills to implement the innovation. Kiswahili is a language predominantly used by the people of Tanzania. At secondary school level, instruction is carried out in English at this level a child who was never introduced properly to the use of English language at lower level will find it difficult to use the language at a higher level of education.

In Africa, preschool education is still an innovation and the education officers should ensure that those hired to teach in preschool understand how the innovation works (Onyango, 2008). In the current situation some learners are likely to leave preschools without having acquired critical English skills such as speaking, listening, and writing. Just because some of the teachers are not familiar with English syllabus content, can't use relevant methods such as songs and play. These methods are critical in delivery and if preschool teachers cannot use these media, it disadvantages learners.

Preschool teachers are required to teach all the subjects. The second objective of the study sought information about whether teachers had relevant skills in handling preschool Math curriculum. Table 1 shows the results.

Table 1 shows that 38\% strongly agreed and 38\% agreed that they can use concepts, symbols; another $42 \%$ strongly agreed, $44 \%$ agreed that they are able to creative arts to teach numbers. These findings imply that majority of preschool teachers are able to handle the Math syllabus; however, $15.6 \%$ face significant challenges.
Of teachers indicated that they had a problem in handling certain aspects of the Maths syllabus. This implies that this number of teachers are likely to affect the acquisition of Math skills in primary schools. Preschool Math curriculum requires that children be taught how to identify numbers, learn about weights and measurements, be able to carry out basic operations of adding and subtracting, and write numbers (TIE, 2016). If some teachers themselves are deficient in content and methodology, then there is a problem that needs to be resolved urgently.

In the open-ended section of the questionnaire which sought information about the ability to use creative arts such as songs to teach math, one teacher indicated that she was not able to do it very well as she had a problem in composing her own songs and using them to teach Maths. She said she often repeated the same song in every activity and sometimes it was not relevant to what was being taught

Math is key to the industrialization of the nation. If the generation prepared to undertake such changes lack math skills, then the dream of having an industrialized nation may not work. This calls for teacher educators to see how best they can help teacher trainees to be able to use creative arts in teaching Maths at a preschool level.

The findings of some teachers not being able to use creative arts to teach Math skills effectively agrees with the observation by Njenga and Kabiru (2001), who indicated that the inability of preschool teachers to teach certain concepts effectively could be due to the fact that their training was not adequate. Njenga and colleagues suggest that when preschool teachers are being hired, the following conditions should be followed: the ability to teach the subject, the ability to interact with children, the ability to understand children's needs.

Perhaps preschool authorities in Tanzania should carefully consider the warning by Chang (2015) who asserts that ignoring preschool education can have very serious consequences to a country. He asserts that the quality of preschool enhances the social, cognitive and numeracy, and development of children. Therefore, poorly implemented preschool programs can be catastrophic to the future of a nation which deserves to become industrialized. 


\section{CONCLUSIONS}

This section presents the conclusions. The conclusions are based on the objectives of the study and the findings and discussion.

The first objective of the study sought information on whether preschool teachers had relevant skills in handling preschool English language curriculum. The study concluded that the majority of teachers indicated that they had relevant skills to handle preschool English language curriculum. However, there are some teachers who indicated that they had challenges, especially in teaching concepts such as doodling and the use of songs.

The second objective of the study sought information about whether they had relevant skills to teach the Maths syllabus. This study concluded that the majority are able. Just like the English language, there are some teachers who are not capable of using some methods.

\section{RECOMMENDATIONS}

This section presents the recommendations of the study based on the conclusions of the study. Regarding the English language, the study recommends that workshops should be organized for teachers on the best way to teach the English language, especially how to teach various Basic English language skills at the preschool level of education. The study also recommends that seminars should be conducted for Math teachers on how to use creative arts such as songs in teaching math at the preschool level of education.

\section{REFERENCES}

Anderson, J.A. (1987). Communication Research: Issues and Methods. McGraw-Hill.

Barnett, W.S. (2005). Preschool Education: a Concept Whose Time Has Come. PrincipalEarly Childhood, 85(1), 14-18.

Best, J.W., \& Khan, J.V. (2006). Research in education $\left(10^{\text {th }}\right.$ ed.). Pearson Education, Inc.

Burns, M.S., Johnson, R.T. \& Assaf, M.M. (2012). Preschool Education in Today's World:
Teaching Children with Diverse Backgrounds and Abilities. Brookes Pub.co.

Bruns, B., Filmer, D. \& Patrinos, A., H. (2011). Making Schools Work: New Evidence on Accountability Reforms. The World Bank.

Calmorin, L. \& Calmorin, M. (2007). Research Methods and Thesis Writing ( $2^{\text {nd }}$ ed.). Rex Bookstore.

Chomsky, N. (1995). Language and Nature. Mind, 104 (413). 1-61.

Cresswell, J. W. (2012). Educational Research: Planning, Conducting and Evaluating Quantitative and Qualitative Research (4 ${ }^{\text {th }}$ ed.). Pearson.

Das, R. C. (1990). Science teaching in schools. Sterling Publishers Pvt. Ltd.

Gay, L.R., Mills, G.E. \& Airasian, P.W. (2012). Educational Research: Competencies for Analysis and Applications (10 ${ }^{\text {th }}$ ed.). Pearson Education, Inc.

Gerdes, J., Durden, T.R., \& Poppe, L.M. (2013). Brain Development in the Primary Years. .G2198. Faculty Publications from CYFC. 77. https://digitalcommons.unl.edu/cyfsfacpub/77

Gichuru, L. M. (2016). Effect of Teacher Quality on Student Performance in Mathematics in Primary 6 National Examinations: a Survey of Private Primary Schools in Gasabo District, Kigali City, Rwanda. http://www.ijern.com/journal/2019/Fe bruary-2019/21.pdf

Gross, N., Giacinta, J. \& Bernstein, M. (1971). Implementing Organizational Innovations: a Sociological Analysis of Planned Educational Change. Basic Books.

HerzfeltKampath, R. \& Ullrich, R. (2016). Examining Teacher Effectiveness Between PreSchool and Grade Three. Centre for American Progress

Hendi, N.S. \& Asmawi, A. (2018). Preschool English Teachers' Practices and Early Literacy Instruction: Montessori vs International Preschool Curriculum. Malaysian Online 
Journal of Education Sciences, 6(2)29-36. https://files.eric.ed.gov/fulltext/EJ1176121.pdf

Hong, X. M. \& Ma, Q. (2015). Evaluation of the Implementation Effect of the Early Childhood 3year Action Plan: Perspectives of International stakeholders. Journal of Education Studies, 1, 115-126.

Hughes, M. (1986). Children and number: Difficulties in learning mathematics. WileyBlackwell.

Japhet, M. (2016). Teachers Scaffolding of Young Children's Mathematics Learning Activities in Pre-primary Schools in Kinondoni District, Tanzania (Masters Dissertation, The University of Dodoma). http://hdl.handle.net/20.500.12661 $/ 1483$

Juma, N. E. (2014). Determinants Of Pre-Primary School Teachers'use of Music As A Medium Of Instruction In Kitale Municipality, Trans-Nzoia County, Kenya (Doctoral Dissertation, School Of Education, Kenyatta University).

Kombo, K. D \& Tromp, L.A. D. (2006). Proposal and Thesis Writing: An Introduction. Paulines Publications.

Krysik, J., \& Finn, J. (2007). Research for Effective Social Work Practice. McGraw-Hill

National Association for the Children (2016). High Quality Early Childhood Educators Are Key to Quality Programs for Children. https://www.naeyc.org

Njenga, A., \& Kabiru, M. (2001). In the Web of Cultural Transition. Bernard Van Leer Foundation.

Nyokabi, K. J. (2018). The Implementation of Early Childhood Development and Education Curriculum in Mathira East Sub-county, Nyeri County, Kenya. (Masters Dissertation, Kenyatta University). https://ir-library.ku.ac.ke

Ojera, D. A. (2016). Impact of Teacher Qualification on Pupils 'Academic Achievement in Kenya Certificate of Primary Education in Public Primary Schools of Migori County,
Kenya. World Journal of Educational Research, 3(7), 1-20.

Onyango, D. (2020). Curriculum Development: Concepts, Designs and Processes in a Tanzanian Perspective. Tridax Africa: Mwanza.

Onyango, D. O. (2008). The Implementation of the Pre School Curriculum in Kenya: A Case of Changamwe Division, Mombasa District Kenya. (Unpublished M.A Thesis, University of Eastern Africa, Eldoret, Kenya).

Oso, Y. \& Onen, D. (2008). A general Guide to Writing Research Proposal and Report: a Handbook of Beginning Researcher. Jomo Kenyatta Foundation.

Richardson, R. (2008). An Examination of Teacher Qualifications and Student Achievement in Mathematics. (Published Master's dissertation, Auburn University).

Stark, R. E. (1980). Stages of Speech Development in the First Year of Life. In: Yeni-Komshian G, Kavanagh, J., Ferguson, C.A. (Ed.), Child Phonology, Volume 1. New York: Academic Press.

Tanzania Institute of Education (TIE). (2016). Teacher's Guide for Pre-Primary Education.

Torto, G.A. (2017). The Implementation of the Basic School English Curriculum: the Case of the Cape Coast Metropolis Ghana. Journal of Education and Practice, 8(8), 166-175. https://files.eric.ed.gov/fulltext/EJ1139052.pdf

Young, B.L. (1997). Teaching Primary Science. Longman.

MoEST. (2016). Curriculum and Syllabus for PrePrimary Education.

Uwezo. (2014). Monitoring Children's competencies in East Africa. www. uwezo.tanzania.or.tz

Zhang, Y., Han, Y., \& Yang, X. (2015). Analysis on the Effectiveness of Preschool Education Teachers Construction in Western China-an Empirical Investigation Based on Shaanxi Province. Creative Education, 6(20), 2152.

125 This work is licensed under a Creative Commons Attribution 4.0 International License. 